\title{
A ARTE DE ESCUTAR: NUANCES DE UM CAMPO DE PRÁTICAS E DE CONHECIMENTO
}

\section{EL ARTE DE ESCUCHAR: MATICES DE UN CAMPO DE PRÁCTICAS Y DE CONOCIMIENTO}

\author{
THE ART OF LISTENING: NUANCES OF A FIELD OF PRATICES \\ AND KNOWLEDGE
}

Maria Suzana de Souza MOURA ${ }^{1}$

Valeria GIANNELLA

RESUMO: Este artigo traz os resultados de uma pesquisa de pós-doutorado com o objetivo de explorar os sentidos, potencialidades e práticas da escuta no contexto da gestão participativa. Trata-se de uma pesquisa qualitativa e de caráter exploratório. As referências teóricas para o tema da escuta são incipientes no campo dos estudos organizacionais e da administração. Encontramos estudos na filosofia, comunicação, educação e psicologia; e incluímos as pesquisas anteriormente realizadas sobre metodologias integrativas para a formação e a gestão social. Adotamos uma abordagem transdisciplinar e dialogamos com saberes múltiplos, tais como os de povos tradicionais e do budismo, bem como com as experiências de gestores entrevistados. Inicialmente, trazemos um breve estado da arte sobre o tema. Na sequência nos detemos sobre os tipos e a importância da escuta no âmbito da gestão e discorremos sobre as dimensões da escuta (de si, do outro, do grupo e do contexto), a partir da experiência dos gestores entrevistados, o que nos permite sinalizar algumas práticas que podem ser utilizadas no sentido de cultivar esta arte. Para concluir, as considerações finais apontam uma síntese preliminar sobre a importância da arte de escutar na atualidade, e, em particular nas organizações e grupos, onde ela deveria ser aprendida e praticada por todos, na medida do possível e nos vários níveis citados acima. Ela é necessária para captar e processar informações, encontrar soluções, para estimular pessoas e grupos a conviverem e criarem juntos e para lidarem criativamente com situações de conflito.

PALAVRAS-CHAVE: Escuta; Metodologias Integrativas; Gestão Participativa

RESUMEN: Este artículo trae los resultados de una pesquisa de pos-doctorado realizada con el objetivo de explorar sentidos, potencialidades y prácticas de escucha en el contexto de la gestión participativa. Es una investigación de caracter exploratorio y cualitativo. Las referencias teóricas para el tema de la escucha son incipientes en los estudios organizacionales y de la administración. Encontramos estudios en filosofía, comunicación, educación y psicología; y nos nutrimos de pesquisas anteriores sobre metodologías integrativas para la formación y la gestión social. Adoptamos un abordaje transdisciplinar y dialogamos con saberes de pueblos tradicionales y del budismo, así como con las experiencias de gerentes entrevistados. Inicialmente, presentamos un breve estado del arte acerca del tema. Seguidamente analizamos los tipos y la importancia de la escucha en la gestión para, posteriormente, reflexionar sobre las dimensiones de la escucha (de sí, del otro, del grupo e del contexto), a partir de la experiencia de los gestores entrevistados, momento en lo cual apuntamos prácticas que pueden ser utilizadas para cultivar esta arte. Para concluir, las consideraciones finales ofrecen una síntesis de la importancia del arte de escuchar en la actualidad. particularmente en organizaciones y grupos, donde debe ser aprendida y practicada por todos, en la medida de lo posible y en los distintos niveles que se mencionó anteriormente. Ella es necesaria para capturar y procesar la información, encontrar soluciones para estimular a los individuos y grupos para vivir y crear juntos y para hacer frente de manera creativa con las situaciones de conflicto.

PALABRAS CLAVE: Escucha; Metodologías Integrativas; Gestión Participativa

Abstract: This article presents the results of a post doctoral research, in order to explore the meanings, potential and practices of listening in the context of participatory management. It is an exploratory and qualitative research study. The theoretical references to the theme of listening are incipient in the field of organizational studies, administration and social management. We find studies on philosophy, communication, education and psychology; and include in previous research on integrative methodologies for training and social management. We adopt a transdisciplinary approach and engage in dialogue with multiple knowledge, as of traditional communities, Buddhism, as well as with the experiences of the group of managers we interviewed. Initially, we bring a brief state of the art on the subject. Following the hold about the types and the importance of listening in management and discuss about the dimensions of listening (of yourself, of the other, of the group and of the the context), driving from the experience of the managers we interviewed, which allowed us pointing out elements that can be used in order to cultivate this art. Finally, the conclusions point a preliminary overview of the importance of the art of listening today, namely, in groups and organizations, where it has to be learned and practiced by everyone, in the limits of possible and in all the dimensions cites before. It is necessary to capture and process information, find solutions, to encourage individuals and groups to live and create together and to creatively deal with conflict situations.

KEY-WORDS: Listening; Integrative Methodologies; Parcipatory Management

\footnotetext{
${ }^{1}$ Professora associada 4, Universidade Federal da Bahia (UFBA)

${ }^{2}$ Professora Efetiva Adjunta III, Universidade Federal do Sul da Bahia Campus Sosígenes Costa, Porto Seguro, Líder do Grupo de Pesquisa Paidéia - e-mail: valeria@ufsb.edu.br
} 


\section{INTRODUÇÃO - UM BREVE ESTADO DA ARTE SOBRE ESCUTA}

Falar de escuta no âmbito da gestão em geral e da gestão social, em particular, pode causar estranhamentos. Temos um longo caminho andado em termos de pesquisa e de práticas no que se refere à gestão participativa (MOURA, 2014)3. Para que esta última aconteça é essencial o diálogo e, neste sentido, escutar de forma ativa, sensível e profunda se faz necessário, como veremos adiante. Porém, em nossa sociedade ocidental pouco nos atentamos para este outro lado da linguagem, como bem nos lembram Alves (2013) e Fiumara (1990).

Rubem Alves no seu ensaio "Escutatória" chama a atenção para o fato de que, no ocidente, existem muitos cursos e apelos à boa oratória, e nada com relação à escuta. Ideia semelhante encontramos em Fiumara (1990), que inicia seu estudo sobre a Escuta lembrando que a cultura ocidental é sustentada por uma racionalidade que estimula o falar, mas não o escutar. Trata-se, segundo a autora, de uma perspectiva voltada para o domínio de uns sobre outros através da linguagem crítica e do discurso, que não valoriza o diálogo nem a escuta. Podemos reconhecer aqui o predomínio do padrão patriarcal em nossa civilização e do lado ativo da consciência humana, pois a escuta, como veremos a seguir, requer um certo grau de introspecção e de abertura para receber e dialogar.

O sentido de escutar vai além do ouvir e inclui o silêncio e o tempo para processar. Tal percepção complementa definições de pesquisadores do campo da comunicação e da educação ${ }^{4}$, para os quais a escuta é um processo de recepção, atribuição de significado e/ou de resposta a partir de uma mensagem verbal e/ou não verbal (WOLVIN; COAKLEY, 1996; PURDY; BORISOFF, 1997). Preferimos apontar para uma perspectiva em que a escuta é um ato social, contextual e dialógico, ou seja, não é individual, nem meramente psicológico, pois a atribuição de significados, assim como a recepção da mensagem e a resposta que será gerada posteriormente são mediadas pela cultura e pelo contexto social (ADELMANN, 2012).

Como ato social e dialógico, a escuta requer uma abertura para reconhecer que o outro é a fonte possível de uma percepção diferenciada e tem algo a contribuir (no processo de aprendizagem, na gestão das organizações, nas políticas públicas etc.). Nesse sentido, podemos assumir desde uma atitude passiva e/ou de acolhimento (apenas registrar o que o outro diz em uma consulta popular, por exemplo) até um padrão de escuta ativa ${ }^{5}$. Esta última é uma modalidade de observação atenta de cada elemento incluído na relação (si mesmo, o outro, o contexto, o particular e a forma), incluindo explicitamente a reflexividade como parte do processo (SCLAVI, 2003). O propósito não é apenas ouvir para registrar uma opinião, é compreender o que está por trás, para além da aparência, uma porta para o diálogo e revisão das próprias certezas, uma chance de enxergar outras possibilidades e modos de ser das coisas.

\footnotetext{
${ }^{3}$ O termo "gestão participativa" é aplicado tanto na área pública estatal e da sociedade civil como na área privada e tem uma longa tradição desde os anos 60 (MOURA, 2014). O termo "gestão colaborativa" é aqui utilizado como sinônimo, embora apresente outras conotações.

${ }^{4}$ As referências que encontramos sobre o tema da escuta na literatura anglo-saxônica, espanhola e portuguesa remetem aos campos da comunicação, da educação e da psicologia.

${ }^{5}$ Encontramos o termos "escuta ativa" em Sclavi (2003) em âmbito de estudos ligados à ação pública em territórios complexos, mas também na psicologia, na Espanha; e nos escritos de consultores de coaching.
} 
Para Sclavi (2003), o bom escutador deve respeitar o interlocutor e ser curioso - abrir-se a outra visão de mundo. Um dos fundamentos disso é a compreensão da realidade como construção social complexa e, portanto, o reconhecimento de seu caráter multifacetado e das várias visões e percepções possíveis sobre o mesmo fenômeno, objeto e situação. Ou seja, é necessário transitar do lugar em que se vê uma única verdade oposta ao diferente, em direção a um posicionamento de abertura para escutar outras verdades; abrindo-se ao diálogo e colocando em xeque suas próprias certezas.

Encontramos o termo "escuta ativa" associado à psicoterapia e à psicologia com base em Rogers (1997), a mesma referência utilizada por Barbier (2008) com a chamada "escuta sensível". Trata-se de escutar o outro para compreender o que está a dizer, evitando o quanto possível avaliar ou julgar. Para Rogers, é necessário abrir-se para esse tipo de escuta pois isso enriquece e torna mais sensível quem escuta, assim como promove a transformação do outro, isto é, de quem está sendo escutado.

Até aqui estamos nos referindo à escuta do outro, geralmente relacionado a uma pessoa, embora Sclavi (2003) inclua também o grupo. Completando e indo além dessa dimensão, há outras a serem agregadas: a escuta de si e do contexto.

Levin (1989) nos traz uma abordagem interessante sobre a "escuta de si", relacionada ao conceito de 'Self', integrando a psicologia junguiana e referências do budismo, além da filosofia. 0 autor nos fala de quatro estágios do desenvolvimento da escuta no ser humano.

No primeiro estágio, quando bebês, nossa escuta é com todo o corpo, o campo sonoro do ser como uma totalidade. Trata-se de uma escuta ecológica, holística, sincrética, sinergética, uma audição profunda, simbioticamente embebida no elemental da ecologia da natureza e em comunhão com a matriz sonora. Receptividade, abertura, totalidade; são características desta fase (arquétipo feminino), um estado pré-ontológico de Ser. No processo de socialização nós perdemos isso.

O segundo estágio vai da infância até a adolescência ou fase adulta. É um tempo de desenvolvimento da audição no sentido da discriminação, imitação e compreensão dos sons; ao mesmo tempo em que o ego se estrutura. Assim a audição se torna pessoal e comandada pelo ego, na vida interpessoal, numa relação marcada pela oposição sujeito/objeto.

No terceiro estágio, já na fase adulta, podemos assumir a responsabilidade da nossa audição e desenvolver uma autodisciplina, auto-observação e crescimento da distinção entre o ego (fixado social e culturalmente) e o Ser (Self), uma estrutura de individuação aberta à mudança, organizada pelos (e identificada com) os processos que vão em direção à aprendizagem e ao crescimento. Assumimos o compromisso de desenvolvimento da nossa escuta como uma prática de compaixão; incrementamos nossa capacidade como escutadores para compreensão e responsividade nas inter-relações.

Poucos aprendem a viver o terceiro e quarto estágios. Neste último desenvolvemos a habilidade de deixar ir e deixar vir como um estilo de escuta. Nós aprendemos a arte de escutar na medida, sem as preocupações do ego. Aprendemos um caminho diferente de canalizar, focar e de pôr a atenção, reconhecendo o manifesto (seres) dentro da totalidade (Self).

Podemos considerar que esses dois últimos estágios são essenciais para as abordagens de 
escuta da qual nos falam Sclavi (2003), Rogers (1997) e Barbier (2008). O segundo estágio, centrado no ego, tende a dificultar a abertura para outras verdades e a percepção do outro desde o outro, a não ser que seja um ego inclusivo. Observamos que nesse estágio egóico a percepção da realidade enquanto objetiva e a ideia de que haja uma única verdade se complementam e sustentam reciprocamente. Por isso, temos dificuldade de exercitar as várias dimensões da escuta - de si, do outro, do grupo e do contexto, pois esta multidimensionalidade requer uma identificação com a totalidade, uma abertura consciente para a compreensão e um deixar ir e deixar vir (primeiro, terceiro e quarto estágios, simultaneamente). Perspectiva semelhante podemos encontrar na abordagem da escuta profunda, como veremos a seguir.

Encontramos o termo "escuta profunda" no Dragon Dreaming (DD), uma abordagem de criação e gestão colaborativa de projetos na linha dos paradigmas emergentes (ecológico e holístico). John Croft, um dos mentores do DD, trouxe de sua vivência com os Mardo, povo aborígene australiano ${ }^{6}$, o Pinakari, expressão que representa "um estado natural de escuta no cotidiano, não só da linguagem verbal falada entre humanos, mas também dos sinais do ambiente mais amplo, da Natureza"'.

Em outro campo de reflexão, orientados pela busca de uma compreensão integrada da cognição humana e de sua relação com a realidade ao nosso redor, Varela, Thompson e Rosch (2003) não falam diretamente de escuta, mas tratam da observação atenta, uma referência ao budismo, que tem plena relação com a escuta profunda, sensível e ativa. Conforme esses autores, a cognição humana depende estreitamente da interação entre dimensão biológica e sociocultural. Isto é, para qualquer cognição acontecer é necessário o engajamento do corpo e seus sentidos: visão, audição, olfato, paladar, tato e a dimensão cinestésica (movimentos e ações), assim como a compreensão e interpretação das linguagens verbal e não-verbal. Ao mesmo tempo, essas "capacidades não podem existir sem a interação com o meio, que, por sua vez, não pode existir sem a presença do indivíduo que o experiencia" (VARELA; THOMPSON; ROSCH, 2003, p.39). Em suma, é a capacidade de escuta em suas inúmeras dimensões, biosocioculturais, que garante a eficácia do processo de cognição do sujeito no mundo.

O caminho da atenção plena apontado pelos autores acima referidos, assim como a escuta ativa, a escuta profunda e outras abordagens da psicologia, representam possibilidades de aprendizagem ímpar para o campo da gestão. Em específico, no campo da gestão social, a escuta é uma competência necessária para o dia a dia da gestão participativa e da liderança compartilhada. Contudo, nosso estudo, nos limites do seu alcance, não encontrou pesquisas que iluminem e fomentem a reflexividade dessas práticas, conceituem adequadamente e considerem plenamente a escuta no campo da Administração e da Gestão Pública e Social, entendendo suas implicações em práticas diversas como as de liderança, trabalho em equipe, gestão participativa, colaboração interorganizacional e gestão de conflitos.

\footnotetext{
${ }^{6}$ Trata-se do povo Manojilidjara Mardo do deserto arenoso da Austrália Ocidental. Para maiores informações sobre o DD, ver http://www.dragondreamingbr (Brasil) e http://www.dragondreaming.org/ (Internacional).

${ }^{7}$ Ana Carolina Beer, integrante e facilitadora da Rede Dragon Dreaming e professora de comunicação na Universidade Federal de Viçosa (MG), em conversa gravada com a pesquisadora/autora no dia 19/04/2015.
} 
Tal carência é apenas parcialmente preenchida pela alusão ao tema que encontramos em artigos sobre Metodologias Integrativas, onde a escuta aparece enquanto prática necessária para o diálogo e a gestão criativa de conflitos, nomeadamente nos moldes de uma metodologia denominada Roda de Escuta. Esta última é identificada como ferramenta de enorme relevância para o campo da educação e da gestão social (GIANNELLA; MOURA 2009; GIANNELLA, 2011; MOURA, 2013). A pesquisa que ora apresentamos tem esses antecedentes e representa uma ampliação desse olhar.

Do ponto de vista da prática, para que possamos avançar na direção de uma gestão colaborativa/participativa, precisamos de metodologias que estimulem o diálogo, o reconhecimento, o respeito e a valorização das diversidades; que fortaleçam nossas capacidades de escuta e de fala consciente, para que a (cri)ação coletiva de conhecimentos, projetos e ações pertinentes e adequadas e a gestão criativa de conflitos sejam possíveis. Trata-se de uma mudança significativa frente aos modelos de gestão e de aprendizagem baseados na hierarquia, nas tomadas de decisão centralizadas e na separação entre quem decide e quem executa.

\section{TIPOS DE ESCUTA, ENTRE AS ABORDAGENS E AS PRÁTICAS}

As abordagens de escuta aqui esboçadas (ativa, sensível e profunda), assim como a atenção plena do budismo, coexistem com outras práticas do senso comum e de campos profissionais e filosóficos. Nelas podemos encontrar alguns fios que se entrecruzam e se diferenciam, no que se refere aos sentidos, ao foco e à intenção da escuta. Se tomamos o desenho de uma espiral, podemos iniciar com a recusa, consciente ou inconsciente, à escuta e seguir com outros tipos, conforme os tópicos que seguem:

- Escuta dispersa: este padrão de escuta é muito comum em nossa cultura, na atualidade. A escuta é experienciada como mera audição de estímulos externos de forma dispersa, sem prestar muita atenção e sem intenção. $O$ ouvir é um ato mecânico, quando acontece ${ }^{8}$;

- Ouvir com foco momentâneo: ou seja, em meio à dispersão paramos, às vezes, para ouvir uma música, uma conversa (do vizinho, de um colega de trabalho, um passarinho cantando); algo que nos chama a atenção e que nos detemos rapidamente e seguimos. Pode ser prazeroso ou não, pode ter desdobramentos ou não, pode levar a uma escuta contemplativa, compassiva, ativa ou, simplesmente, passar;

- Escuta contemplativa: inclui o ouvir com foco, intenção e abertura do coração/mente para contemplar (usufruir de um canto, uma orquestra, por exemplo);

- Escuta que inclui o ouvir, com foco, intenção e abertura da mente para conhecer: por exemplo, o argumento e os dados que o outro apresenta em um processo de negociação, um debate, aula ou palestra;

\footnotetext{
${ }^{8}$ Essa noção de escuta dispersa faz parte da experiência comum, mas também quem pratica o magistério ou atua com grupos sabe o
} quanto esse padrão é recorrente e pouco eficaz. 
- Escuta receptiva, ouvir com foco, intenção e abertura do coração/mente para receber, por exemplo: a verdade transmitida do/a mestre/a - o sentido da filosofia dos estoicos; a sabedoria dos anciãos/anciãs - o sentido da cosmovisão africana; o que Deus nos "fala" - o sentido do cristianismo;

- Escuta como atenção plena e consciência dos processos do corpo-mente' ${ }^{9}$ de inserção e reconstrução contínua da rede de interconexões que constituem a realidade, na perspectiva do budismo;

- Escuta que vai além do ouvir, com foco, intenção e abertura do coração/mente em uma atitude de acolhimento compassiva (de uma pessoa ou um grupo, por exemplo): escuta compassiva (Thich Nhat Hanh, monge budista); escuta sensível ou ativa (abordagem da psicoterapia, psicologia...)

- Escuta que vai além do ouvir, com foco, intenção e abertura do coração-corpo-mente para escutar o outro (pessoa, grupo), ao mesmo tempo que se escuta (sensações, emoções e pensamentos) e, quando necessário, faz perguntas criativas para potencializar a expressão e o dar-se conta da pessoa ou grupo: escuta ativa, na linha de Sclavi e na prática do coaching.

- Escuta profunda com todos os sentidos, através da integridade do ser, enquanto estado natural na relação com o ambiente, as pessoas, o manifesto e o não manifesto: aborígenes australianos (Dragon Dreaming).

A compreensão dessas possibilidades de escuta pode nos levar a uma escolha consciente, potencializando nosso modo de estar no mundo e nas relações, em qualquer contexto. Com tal consciência e habilidades podemos transitar para um patamar de mais integridade, se assim desejarmos e necessitarmos. Passar de um tipo de escuta disperso para um focado requer o dar-se conta e pôr-se em movimento no sentido do aprendizado.

A escuta na primeira e segunda condição pode nos levar a situações de desconforto e estresse, caso o que escutamos crie uma dissonância (a conversa ou briga de vizinhos, uma máquina ligada produzindo forte ruído ou uma música alta e nada atraente, por exemplo). Essa dissonância acontece, não necessariamente e nem só, pelo conteúdo como também pelo timbre, tom, ritmo, enfim, pela frequência vibratória. Isto é, campos de energia que são acionados e impactam em nossos corpos e em alguns momentos e circunstâncias ativam memórias celulares que fazem aumentar a descarga de adrenalina e cortisona. Esses hormônios quando em excesso podem causar palpitações, angústias e ansiedades.

Os tipos de escuta intencionais são adequados para determinados contextos e propósitos e podem ser mesclados. Passear por eles, reconhecê-los nos permite adentrar em um campo vasto de conhecimento e de práticas fundamentais para a gestão colaborativa. Ao mesmo tempo, distinguir 
essas possíveis formas de escutar pode nos ajudar a iluminar a relação existente entre prática de escuta e concepção implícita de realidade que o sujeito está adotando ou que, mais estavelmente, lhe pertence.

De forma sintética, podemos dizer que o processo de escuta pode implicar a assunção/apreensão de uma realidade objetivada ou, diversamente, a exploração aberta de uma realidade assumida como multidimensional e complexa. Nesse sentido, afirmamos que a escuta ilumina uma dimensão epistemológica da relação entre o sujeito e a realidade que ele habita, isto é, o tipo de concepção da realidade assumida por ele.

Tipicamente, as interpretações da escuta enquanto a) audição e decodificação de mensagens, b) desvelamento de uma verdade já posta (dentro de um universo onde a verdade é sempre, e por definição, uma) ou de um erro que ameaça e desafia a verdade, nos remetem a uma visão objetivada de realidade.

Dentro de uma visão complexa (multidimensional, relacional e construtivista) de realidade, a possibilidade de uma escuta aberta para a exploração e coprodução dos significados, através da interação com "o mundo do outro" e as "razões do outro", não depende, exclusivamente, de uma disposição voluntarista. Essa perspectiva de escuta parte do reconhecimento de que o ponto de vista de uma pessoa é parcial e limitado demais para que se possa dar conta do desafio de atuar na realidade. E mais, é preciso incluir a razão dos outros (outros pontos de vista), até para se poder sobreviver, em nosso mundo complexo ${ }^{10}$.

Assim, se assumimos que o mundo da gestão social, gestão democrática e colaborativa é, por definição, um mundo complexo, habitado por múltiplas lógicas e razões, valores e interesses todos legítimos, pelo menos até o momento em que não impedem a possibilidade de outros interesses e razões também se manifestarem - daí compreendemos que o desafio da convivência está intimamente relacionado à escuta enquanto prática relacionada à exploração de mundos possíveis (SCLAVI, 2003), sendo esta uma primeira porta para compreendermos a importância da escuta.

\section{IMPORTÂNCIA DA ESCUTA CONSCIENTE}

A partir das considerações acima, especialmente da distinção epistemológica que foi traçada, podemos destacar a importância da escuta, como prática exploratória e criativa, para os gestores, os educadores/aprendizes e para profissionais dos mais diversos campos. Os benefícios dessa perspectiva de escuta são variados:

- A escuta (ativa, sensível, profunda), quando exercida por quem assume o papel de liderança nas organizações e nos processos de aprendizagem, propicia o engajamento dos colaboradores e aprendizes. Isso porque pode contribuir para a emergência dos seus potenciais, estimulando-os a agirem e expressarem-se com base em suas habilidades e tendo em vista as reais necessidades coletivas e pessoais. O que, por sua vez, facilita a resposta criativa aos desafios encontrados na gestão e nos processos de aprendizagem.

\footnotetext{
${ }^{10}$ Esta visão não é apenas coerente com as mais recentes abordagens epistemológicas da complexidade; mas com tradições culturais não
} ocidentais a exemplo da IorubáN (africana), como confirmado pela narração do mito do espelho em Machado (2009, p. 22). 
- A escuta (ativa, sensível, profunda) facilita a interação das pessoas em ambientes de diversidade cultural, seja ela nas organizações ou nos âmbitos mais variados da sociedade contemporânea. A diferença/complexidade acentuada em nossas sociedades e organizações proporciona a cada dia mais situações de interculturalidade, isto é, contextos onde diversas premissas implícitas orientam as várias leituras e formas de ação no mundo; onde a tendência à negação do diferente é corriqueira, o que torna a arte de escutar, relacionada à gestão criativa de conflitos ${ }^{11}$, uma competência cada vez mais necessária para abrir portas à convivência e à possibilidade de ação conjunta entre diferentes (SCLAVI, 2003).

- A escuta favorece os processos coletivos de trabalho e de organização, instaurando efetivamente capacidades de indagação criativa, pensamento divergente (fora dos quadrados e dos limites dados), exploração de opções e possibilidades não óbvias. A habilidade da escuta, exercida em grupos em um ambiente colaborativo, cria campos fecundos para ativar e sustentar a inteligência coletiva.

- A escuta estimula uma cultura participativa e democrática, tanto no seio da sociedade quanto de suas mais diversas organizações. A prática da escuta é um dos requisitos para o desenvolvimento de processos participativos e colaborativos. Tais processos tendem a emperrar, em maior ou menor medida, na perspectiva epistemológica que reafirma - de forma contraditória com respeito às intenções declaradas - a legitimidade de apenas uma visão de mundo, em vez de aceitar a hipótese e fomentar a prática da exploração e convivência entre visões distintas. Essa perspectiva, ainda hegemônica, está entranhada em nossos modelos mentais, memórias e comportamentos (GIANNELLA; MOURA, 2009).

- A escuta abre caminhos para reconhecermos os conflitos como oportunidades de aprendizagem nas organizações, indivíduos e sociedades. Dentro de uma visão epistemológica baseada na premissa da verdade única, o conflito expressa negação. De forma diferente, ao assumirmos uma visão de mundo complexo e multíplice, o conflito torna-se uma oportunidade de aprendizagem por evidenciar diversos modos possíveis de perceber dada realidade. No entanto, para que esta possibilidade seja efetivada, precisamos treinar as capacidades de escuta criativa e, com elas, a competência de gestão criativa de conflitos (SCLAVI, 2003).

- A escuta prepara os gestores, educadores, profissionais e pessoas em geral para lidarem com o caos e a adversidade, favorecendo o trabalho voltado para a criatividade e a inovação.

${ }^{11} \mathrm{Na}$ visão de Sclavi (2003), a gestão criativa de conflitos é um dos elementos de um tripé, juntamente com a escuta ativa e a autoconsciência emocional. Os três elementos, cada um sustentando e dependendo da prática do outro, nos permitem uma atuação à altura das demandas e desafios da complexidade contemporânea. Da mesma forma, podemos afirmar serem ferramentas cruciais para gestores de todo tipo em nossas sociedades. Nomeadamente, a gestão criativa de conflitos implica a assunção consciente da complexidade do real, enquanto intrínseca diversidade dos pontos de vista dos sujeitos. Uma vez dado esse passo e aberta a porta à possibilidade de se escutar as verdades dos outros com mente aberta e sem julgamentos prévios, também emerge a possibilidade de se enxergar criativamente pontos de encontro, atendendo ao grande desafio da contemporaneidade, isto é, a realização das possibilidades de convivência. 
Além disso tudo, ainda nos parece importante destacar a importância da arte de escutar com relação à ênfase dada à participação dos atores sociais nas políticas públicas, projetos sociais e organizações em geral, nas últimas décadas, tanto na academia, como fora dela (MOURA, 2014). Ao levarmos em consideração as práticas de participação e de gestão participativa vamos encontrar diferentes padrões, mais ou menos coerentes com as intenções declaradas. Dito de outra forma, é comum que a participação seja utilizada como um meio de cooptação e de legitimação de políticas e projetos sociais (MOURA, 2014), mas também acontece que os gestores carecem de instrumentos epistemológicos e metodológicos adequados para cumprir seus objetivos. Nomeadamente, apontamos aqui a falta das capacidades de escuta das visões e reais anseios dos atores sociais, e o compromisso com a formação na arte de escutar como caminho interessante para entrar nesse campo desafiador.

Em contextos de ampliação da democracia e do exercício da cidadania, em que convergem demandas sociais por participação e a vontade real de governos em prol de uma gestão participativa, a escuta pode ganhar destaque em um sentido duplo: de um lado caberia aos cidadãos escutar as propostas e as prestações de contas dos governos, bem como as ponderações dos técnicos; de outro, caberia aos técnicos e governantes escutar os posicionamentos e aspirações das comunidades. Algo semelhante pode acontecer em situações cujo propósito é melhorar o desempenho das políticas públicas, projetos e ações nas organizações.

O que sinalizamos até aqui sobre a importância da escuta para a gestão colaborativa e participativa é apenas uma parte do que encontramos, nas entrevistas com gestores e na literatura consultada. Podemos ir além e trazer outros aspectos que revelam as dimensões, o potencial e as práticas.

\section{ELEMENTOS METODOLÓGICOS DA PESQUISA EMPÍRICA}

No sentido de contribuir com a revelação do campo de práticas e com a construção do conhecimento sobre a arte de escutar realizamos, ao longo da pesquisa, 16 entrevistas semiestruturadas com gestores de organizações públicas, privadas e da sociedade civil. As entrevistas foram realizadas no período de janeiro a agosto de 2015, sendo algumas presenciais e outras via Skype. Elas foram gravadas, transcritas e tabuladas a partir das quatro dimensões da escuta: de Si, do Outro, do Grupo e do Contexto (interno e externo à organização).

A escolha da entrevista enquanto método, bem como sua realização, foi se afinando com a própria temática de estudo. Conforme Ornellas (2011), a "entre-vista" nos possibilita experienciar um espaço de troca de sentido entre entrevistador e entrevistado, onde ambos os sujeitos são portadores de uma fala e de uma escuta as quais aproximam o objeto de investigação e de teorização do pesquisador. Outra referência possível é a "entrevista narrativa" (FLICK, 2004), na qual uma questão referida ao tópico de estudo visa estimular a narrativa principal d@ entrevistad@ e aprofundar em seguida as possíveis reflexões teóricas que a vivência relatada permite e suscita. Em nosso caso, solicitamos aos gestores que lembrassem de experiências significativas no seu ambiente de trabalho, as quais evidenciassem a importância da escuta nos quatro níveis (de si, do outro, do grupo e do contexto).

Vamos apresentar aqui alguns elementos de sistematização das entrevistas, com o auxílio 
da tabela 1, incluindo as reflexões surgidas ao longo do processo, inspiradas pelas leituras e entrevistas.

\section{A ARTE DA ESCUTA: DIMENSÕES, POTENCIAL E PRÁTICAS ${ }^{12}$}

Inicialmente, podemos dizer que a arte de escutar na gestão colaborativa/participativa vai além do ouvir; inclui o olhar, a observação atenta, o sentir o corpo, sensações e sentimentos, a reflexão e, conforme o caso, a elaboração de perguntas provocadoras e a verificação da pertinência. Requer atitude de entrega, atenção e não julgamento, bem como reconhecer quando é necessário dar limites à escuta. Essa compreensão inclui elementos da escuta ativa, sensível e profunda e avança em relação ao que temos encontrado na literatura, conforme sinalizamos na introdução.

Essa arte se processa em várias dimensões: de si, do outro, do grupo e/ou do contexto (interno e externo a organização). Essas dimensões de escuta podem ser experimentadas simultaneamente, sendo este um ponto essencial de aprofundamento da pesquisa. Assim, trazemos agora alguns elementos particularmente relevantes, retirados das entrevistas com os gestores, focando na sua importância para a gestão e nas práticas relativamente a cada uma das dimensões citadas. Escolhemos esses dois aspectos por atuarmos no campo do ensino da administração e da gestão social e por entendermos que a experiência dos gestores entrevistados pode contribuir com a produção e difusão do conhecimento sobre a escuta consciente, sua importância e práticas que favorecem o aprendizado.

\section{TABELA 1 - Dimensões da arte de escutar}

\begin{tabular}{|c|c|c|}
\hline Dimensões & Importância para a gestão & Práticas que favorecem a escuta \\
\hline Escuta de si & $\begin{array}{l}\text { - Perceber o grau de (in)satisfação com o trabalho que está } \\
\text { realizando } \\
\text { - Checar os próprios sentimentos, conceitos e ideais frente } \\
\text { às exigências do cargo que ocupa } \\
\text { - Qualificar a escuta do outro no processo de gestão } \\
\text { - Evitar atitude impulsiva e reativa e o acirramento de } \\
\text { conflitos } \\
\text { - Perceber e compreender o que provoca em si a presença e } \\
\text { a fala do outro } \\
\text { - Perceber a sua própria disposição para a escuta do outro } \\
\text { - Exercitar o não julgamento o acalmar da mente } \\
\text { - Trazer a resposta ou não resposta adequada ao momento } \\
\text { do outro. } \\
\text { - Encontrar soluções aos desafios vivenciados } \\
\text { - Conectar valores, conhecimentos e habilidades pessoais no } \\
\text { processo decisório }\end{array}$ & $\begin{array}{l}\text { - Jogo da empatia - um diálogo entre si e o "outro" dentro de } \\
\text { si - colocar-se no lugar do outro para expandir a } \\
\text { compreensão e incluir outras possíveis percepções } \\
\text { - Diante de desafios: importante parar, ir para um lugar de } \\
\text { natureza, sozinha, abrir-se para a escuta; assim, emergem } \\
\text { respostas novas } \\
\text { - Quando perceber que não está bem emocionalmente, optar } \\
\text { por ficar mais recolhida na sala } \\
\text { - Lembrar do que tem para fazer quando desperta pela } \\
\text { manhã e observar se está com ânimo ou com desânimo }\end{array}$ \\
\hline
\end{tabular}

\footnotetext{
${ }^{12}$ Uma interessante contribuição para orientação das práticas de escuta ainda é oriunda de Sclavi (2003) e foi traduzida em Giannella; Moura (2009) e em Giannella; Araújo; Oliveira Neta (2011). Trata-se das sete regras da arte de escutar, em que diversas das colocações aqui apontadas são traduzidas de forma sucinta e operacional para orientar aqueles que se propõem a praticar.
} 
equilíbrio, minha maturidade." (gestora de empresa de consultoria)

"Às vezes, umas pessoas chegam falando alguma coisa e se eu não tô muito centradinha eu já chego explodindo em cima do outro, tomo decisões erradas às vezes. É diferente quando estou em equanimidade, estou centrada, nem aborrecida, quando não tô bem, nem eufórica, quando estou bem. ... Eu acho importante a meditação ... fazer exercício, um pouco de yoga, ir à praia, contato com a natureza, respiração e contato com a respiração. ... Respirar e vir pra cá (apontou para o coração), pro centro ..." (gestora e proprietária de restaurante)

"Então, o meu termômetro é exatamente quando eu acordo e olho o meu dia. Se aquilo me der um 'que legal', pronto, á tudo certo. Se aquilo não me der esse 'que legal', e vier, 'puxa, fazer isso...' eu vou fazer, mas aquilo é o meu termômetro de dizer, vou mudar de área, vou pedir a meu chefe pra trabalhar com outra coisa, ou então, dentro do meu trabalho eu vou criar de uma outra forma, porque esse é o meu termômetro." (gestora em empresa pública)

Ao mesmo tempo, a escuta de si é essencial para o gestor tomar decisão, trazendo à tona os valores, conhecimentos e habilidades para balizar escolhas; ou mesmo silenciando e afastando-se para um outro local (de Natureza, por exemplo), onde possa reconectar-se com a sabedoria interior, com o seu centro.

\begin{abstract}
Na minha experiência (a escuta de si) é sistemática, eu reflito a respeito de cada situação, principalmente nas mais importantes. Ouvir a si mesmo significa buscar, conscientemente ou não, nos meus valores, na minha história, no meu conhecimento e habilidades, os elementos fundamentais para tomada de decisão. Aliás, ouvir a si mesmo talvez seja a mais preponderante situação, quando você tem que tomar uma decisão, ou tem que tomar um rumo na vida. ... Agora, também tem situações nas quais eu não preciso refletir muito, principalmente sob pressão, numa necessidade de decidir rapidamente, onde aquelas variáveis já estão incorporadas no meu conhecimento e nos meus valores, ..." (gestor em grande empresa privada)

“(...) parar e ouvir, o que for, porque nesse momento eu já não separo, o que vem para eu ouvir é de mim, do outro, do ambiente. Então parar e ouvir tem muito a ver com prática de reconexão, de meditação, o nome que seja, uma prática de escuta. E nesse momento, essa prática de ir pra algum lugar da natureza e se sentar e estar sozinha, parar, fazer uma escuta profunda e o que vem, o que emerge daí, o que na teoria $U$ chama de presenciando, já me orientou muito, aparecem coisas que eu nem imaginava." (gestora de grupos de criação de projetos)
\end{abstract}

Para melhor compreender o outro, às vezes é necessário colocar-se no lugar do outro e fazer um exercício de escuta em si:

\begin{abstract}
"O dialogo interno é constante, né? Às vezes essa escuta é feita quando eu busco um exercício de empatia. Dizer pra mim mesma, reposicionar-me, como pode ser a opinião do outro a respeito de alguma coisa, que na verdade sou eu falando comigo mesma. Então, às vezes eu me dou essa oportunidade de travar esse diálogo comigo mesma, me escutando a partir de uma posição que não é a minha, trocando de posição, trazendo uma empatia na situação, pra ver se eu consigo ter mais clareza nessas situações. .... Acho que pra fazer a gestão, conduzir pessoas e processos você tem que se colocar no lugar do outro, pra aumentar a capacidade de compreensão. Mesmo sabendo que eu estou limitada, que sou eu com a minha história de vida e minha formação que estou fazendo esse diálogo." (gestora de empresa pública)
\end{abstract}

A escuta do outro requer, ainda, autoconhecimento:

Então, qualquer pessoa que eu for escutar, eu paro, respiro, olho bem a pessoa, percebo o que tá acontecendo, percebo como tá a sintonia pra poder realmente fazer essa escuta ativa,... sem 
autoconhecimento eu não conseguiria jamais fazer uma escuta ativa, ou uma comunicação compassiva, ou ajudar os outros nas suas necessidades. ... Eu tenho que me ouvir pra poder usar todos os meus sentidos, pra trazer exatamente o que você tá precisando ouvir e escutar e de uma forma que seja compreensível pra todas as pessoas." (gestora de organização da sociedade civil)

$\mathrm{Na}$ realidade e na prática da gestão, os vários níveis de escuta ocorrem, muitas vezes, simultaneamente, mesmo que não nos demos conta. o depoimento de uma entrevistada, gestora em empresa pública, evidencia a importância da escuta para a gestão nos níveis anteriormente citados:

\footnotetext{
"Então, a escuta é uma ferramenta de gestão e é uma ferramenta de comunicação. Eu acho que a escuta ajuda a gente a ser comunicado de algo e, a partir da percepção que tenho daquilo que me chega, ela pode gerar resultados. Ela pode trazer um resultado a partir daquilo, seja de mim comigo mesmo, seja de mim com a equipe, de mim com as pessoas ao meu redor e com a corporação, que também me diz o tempo todo o que espera de mim. Então, é um pouco isso. o como se faz, a primeira coisa é essa disponibilidade de estar aberto a receber, a perceber, a ficar atento ao que os cenários lhe trazem. Seja entre pessoas, seja com a gente mesmo, o que está ao meu redor, que contexto é que eu tô envolvida?. Então, a primeira coisa é a gente perceber e querer perceber isso, pra que a gente não crie interpretações distorcidas de uma realidade que é nossa, que às vezes vira uma realidade impositiva".
}

Ao mesmo tempo em que a arte de escutar traz benefícios para a gestão, apresenta desafios e requer limites. Por exemplo, a escuta de si pode levar a uma escolha que não é mais adequada para o contexto da organização e do grupo no momento. De acordo com uma entrevistada: "A escuta acontece com os ouvidos da cabeça e os ouvidos do coração, logo, o sentimento, assim como as premissas implícitas (do gestor), podem levar a um caminho distinto do que a razão analítica indica; razão esta, que pode ser evidenciada por outra pessoa".

Uma outra evidência é a necessidade de dar limites à escuta do outro na organização ou grupo, por exemplo: quando as sugestões ou ponderações do outro acontecem no momento em que uma decisão já foi tomada ou está sendo implementada e não há como voltar atrás; e quando em reuniões se perde a direção e o alinhamento com o objetivo pré-definido. É o que esclarece um dos gestores entrevistados: "É lógico que tem situações em que o ouvir se torna até um problema. Porque se pede para mudar situações as quais você não tem mais como mudar e tem que aplicar a decisão. (...) há reuniões, encontros que são participativos. Mas tem momentos em que essa participação tem um limite, aí você tem que participar que (a decisão já está sendo encaminhada)."

Conforme sinalizamos, o propósito aqui é evidenciar o potencial do campo da arte de escutar para a gestão, incluindo o aspecto das práticas. Ainda sobre este último daremos breves esclarecimentos sobre duas que foram citadas ao longo do texto: Pinakari e Roda de Escuta.

Conforme apresentamos na introdução, o Pinakari é um estado de escuta profunda (do ambiente, do outro, do grupo e de si) dos Mardos (aborígenes australianos) e que foi adaptado por John Croft para o contexto da criação e gestão colaborativa de projetos (Dragon Dreaming). Trata-se de uma ferramenta que favorece a escuta pois visa: diminuir a dispersão mental em encontros e reuniões de trabalho; ativar a presença pessoal; e contribuir com a emergência da inteligência coletiva. O Pinakari, é um convite para exercitarmos uma escuta profunda, através do contato com nosso corpo (a natureza mais imediata), com a respiração e a força da gravidade que atua em nós ${ }^{13}$. 
Assim, silenciamos a mente e em um estado de presença, na perspectiva da mente incorporada de Varela, Thompson e Rosch (2003), podemos exercer uma escuta e fala mais conscientes e apropriadas ao contexto de cada momento, pelo enraizamento da consciência.

Outra prática que merece destaque é a Roda de Escuta que bebe das experiências de círculos de conversa e decisão (conselhos) de diversos povos antigos e vem sendo reeditada a partir das abordagens da Escuta Ativa (SCLAVI, 2003) e das Metodologias Integrativas (GIANNELLA; MOURA, 2009). As experiências que temos desenvolvido com estudantes e em outros contextos, assim como a prática relatada por uma das entrevistadas, revelam o potencial da forma da reunião (círculo), associada ao estabelecimento de regras, incluindo o bastão da fala posto no centro do círculo e utilizado por quem deseja falar. Um dos compromissos é de que a pessoa com o bastão fale desde o seu centro, naquilo que é essencial e, ao mesmo tempo, os demais se abrem para a escuta da pessoa que está com a palavra, atenta às possíveis reações em $\mathrm{si}^{14}$.

\section{CONSIDERAÇÕES FINAIS}

Iniciamos nosso artigo falando de um possível estranhamento que o tema escolhido pode causar, mesmo em um contexto que põe ênfase sobre a gestão participativa/colaborativa, a qual se depara permanentemente com a necessidade do diálogo, da co-criação coletiva e de gestão criativa de conflitos. O estranhamento maior, no entanto, estaria ligado à irrelevância socialmente atribuída ao escutar com relação ao falar.

A importância do ato da escuta é comumente negligenciada, ou, quando aparece, sofre por uma concepção simplória, a partir da abordagem reducionista que leva a considerar dignas de atenção apenas a linguagem racionalmente orientada, a linearidade do raciocínio e a instrumentalidade da ação. Ao falarmos de escuta costuma-se pensar no simples processo de ouvir a fala de alguém; pouco encontramos tematizada a questão de escutar a si próprio em suas múltiplas e complexas manifestações expressivas (corpomente); de escutar aos outros além das palavras proferidas, nas dimensões emotivas, na linguagem corporal, na capacidade simbólica; de escutar aos organismos emergentes que são os grupos, organizações etc.; por fim, de escutar os lugares em suas histórias explícitas e escondidas, suas marcas, seus potenciais. Ressaltamos aqui a importância de uma escuta que estamos qualificando enquanto "arte de escutar", através de um movimento de aprofundamento das abordagens da escuta ativa, sensível e profunda, integrando, ao mesmo tempo, o que emerge do campo empírico. Essa arte se processa em vários níveis: de si, do outro, do grupo, da organização e/ou do contexto.

Podemos dizer que a arte de escutar vai além do ouvir: inclui o olhar, a observação atenta, o sentir o corpo, sensações e sentimentos, a reflexão e, conforme o caso, a elaboração de perguntas

\footnotetext{
${ }^{13}$ Informações sobre o passo a passo da prática em http://www.dragondreaming.org/es/pinakarri-escucha-profunda/.

14 Não temos o espaço aqui para desenvolver melhor os elementos aqui destacados. Alguns aprofundamentos encontram-se em Giannella e Moura (2009) e em Giannella, Araújo, Oliveira Neta (2011), mas temos clareza de que merecem maiores amadurecimentos em virtude de sua relevância nos ambientes de aprendizagem e de gestão, principalmente quando se trata da gestão social Especificamente sobre o bastão da fala, ou objeto falante, ver: http://www.aada.org.br/page_saibamais.php?tipo=artigo\&id=4 e http://heatherplett.com/2015/06/why-we-need-more-talking-pieces/
} 
provocadoras e a verificação da pertinência. Requer atitude de entrega, atenção e não julgamento, bem como reconhecer quando é necessário dar limites à escuta. Níveis diversos de escuta podem ser experimentados simultaneamente, sendo este um ponto essencial para aprofundamento da pesquisa sobre o tema.

Nas organizações e grupos, a arte de escutar é fundamental e deveria ser aprendida e praticada por todos, na medida do possível e nos vários níveis citados acima. É necessária para captar e processar informações, encontrar soluções, para estimular pessoas e grupos a conviverem e criarem juntos e para lidarem criativamente com situações de conflito.

O diálogo com os autores e os saberes tradicionais, as reflexões levantadas pelas entrevistas dos gestores e as nossa próprias experiências e intuições nos levam a afirmar que a arte de escutar é uma competência cada vez mais indispensável em nossas sociedades complexas. Aqui a convivência intercultural ou, especificamente, os processos de gestão participativa nos mais variados campos, assim como a educação, enquanto dedicação a um objetivo comum que exige cooperação de atores diferentes, pedem o treino amplo e generalizado dessa arte. Ela implica e depende da assunção de uma nova postura paradigmática para poder se materializar, postura em que a dimensão teórica e a experiencial são entrelaçadas, fortalecendo-se mutuamente.

Estamos convencidas de que a perspectiva que adotamos tem a ver com um movimento posto na realidade social que nos pede para aceitar a multiplicidade das razões e dos pontos de vista; para acolher a complexidade do humano enquanto ser "sentirpensante" e os paradoxos da comunicação que o caracterizam; nos pede para abandonar a certeza de que o mundo que conhecemos/enxergamos seja o único possível e para nos abrir a outros campos de possibilidades que emergem. Uma nova forma de pensar/experienciar o mundo se apresenta assim que nos familiarizamos com esta arte. 0 que precisamos é de ocasiões para que isso possa acontecer.

\section{REFERÊNCIAS BIBLIOGRÁFICAS}

ADELMANN, Kent. The Art of Listening in an Educational Perspective: Listening reception in the mother tongue. UMEA University/Sweden: Education Inquiry, v. 3, n. 4, p. 513-534, 2012.

ALVES, Rubem. Escutatória. http://rubemalves.com.br/site/10mais_03.php. Acesso em 10/02/2013 BARBIER, René. Las nociones-bifurcaciones en la investigación-ación, Visión Docente Con-Ciencia, Puerto Vallarta: C. E. U. Arkos, Ano VIII, no 45, nov-dez 2008, p. 05-20.

FIUMARA, Gemma, Corradi. The Other Side of Language: A Philosophy of Listening. New York: Routledge, 1990.

FLICK, Uwe. Uma introdução à pesquisa qualitativa. Porto Alegre: Bookman, 2004.

GIANNELLA, Valéria; ARAUUJO, Edgilson Tavares de; OLIVEIRA NETA, Vivina Machado de. As Metodologias Integrativas como caminho na ampliação da esfera pública. In: SCHOMMER, Paula Chies; BOULLOSA, Rosana de Freitas (Org.). Gestão social como caminho para a redefinição da esfera pública. Florianópolis: Editora UDESC, v. 1, p. 139-164, 2011.

; MOURA, Maria Suzana. Gestão em rede e metodologias não convencionais para a

gestão social. Salvador: Editora CIAGS, 2009. v. 2. (Série Editorial CIAGS / Roteiros Gestão Social).

LEVIN, David M. The Listening Self - Personal Growth, Social Change and the Closure of Metaphisics. London: Routledge, 1989.

OLIVEIRA NETA, Machado, Vivina. Diálogo e gestão criativa de conflitos: método centrado na complexidade do pensamento e simplicidade da ação. Salvador: Solisluna editora, 2016.MARIOTTI, Humberto. Um método de reflexão conjunta e observação compartilhada da Eeperiência. Disponível em: www.geocities.com/pluriversu. Acesso em: 07/09/2014. 
MORAES, Maria Cândida; TORRE, Saturnino. SentiPensar: fundamentos e estratégias para reencantar a educação. Petrópolis: Vozes, 2004.

MOURA, Maria Suzana. Gestão Participativa. In: BOULLOSA, Rosana de Freitas (Org.). Dicionário para a formação em Gestão Social. Salvador: CIAGS/UFBA, 2014. p. 74-76. Metodologias integrativas: abrindo novos caminhos para a criação coletiva na gestão social. Salvador, Revista Interdisciplinar de Gestão Social (RIGS): v. 2, n. 3, set/dez 2013, p. 179-188. www.rigs.ufba.br

ORNELLAS, Maria de Lourdes. [Entre]vista: a escuta revela. Edufba: Salvador, 2011.[entreAS, Maria de Lourdes. $\backslash 000$ esse padr a nossa propria rando as referencias aseguida as posseitos possuem 000000000000000000

PURDY, Michael; BORISOFF, Deborah, Eds. Listening in Everyday Life. A Personal and Professional Approach. Lanham: University Press of America, 1997.

ROGERS, Carl. Tornar-se pessoa. São Paulo: Martins Fontes, 1997.

SCLAVI, Marianella Arte di ascoltare e mondi possibili. Milão: Ristampa Bruno Mondadori, 2003.

VARELA, Francisco; THOMPSON, Evan; ROSCH, Eleanor. Mente incorporada: ciências cognitivas e experiência humana. Porto Alegre: Artmed, 2003.

WOLVIN, Andrew. D.; COAKLEY, Carolyn. G. Perspectives on Listening. Norwood: Ablex Publishing, 1996. 